\title{
ist \\ A noção de determinismo na física e seus limites
}

\author{
Michel PATY
}

\begin{abstract}
药
RESUMO

A idéia de determinismo, proposta para estender e generalizar a causalidade física pelo acréscimo em particular da consideração das condições iniciais, constituiu-se desde então na referência ideal de todo conhecimento científico e foi considerada como insuperável. Todavia, esse ideal ver-se-á superado em várias direções: pelas modificações subseqüentes à causalidade relativística; pelos sistemas dinâmicos "não-lineares" deterministas, cujo comportamento pode no final ser totalmente não-previsível; pelos problemas levantados pela física quântica ("redução" da função de estado e predições probabilistas). Os dois últimos casos tornam evidentes os limites das noções de causalidade e de determinismo, mostrando que o conhecimento atual pode superá-las em muito, além de sugerirem interrogações a respeito do sentido realmente físico das grandezas utilizadas na teoria. Quando consideramos as grandezas mais significativas do ponto de vista das características dos fenômenos físicos, a causalidade se apresenta diferente e o determinismo se mostra antropologicamente centrado e ineficiente. Deixam, desse modo, lugar à consideração dessa outra categoria mais significativa, a saber, a de necessidade, que independe de nossas escolhas conceituais e teóricas e tem, ao mesmo tempo, a capacidade de regulá-las.
\end{abstract}

Palavras-chave • Causalidade. Ciência. Completude. Condições iniciais. Determinismo. Espaço. Física quântica. Grandeza física. Invariância. Necessidade. Relatividade. Sistemas dinâmicos. Tempo.

\section{INTRODUÇÃO: GAUSALIDADE E DETERMINISMO NA FÍSICA GLÁSSICA}

As noções ou categorias de causalidade e de determinismo acompanharam a formação das ciências modernas e, primeiramente, a formação da física. O uso corrente em nossos dias tende, freqüente e erradamente, a confundi-las nos questionamentos que são feitos pela própria física. Pareceu-nos desejável tentar esclarecer esses pontos de maneira sintética e comparativa, seguindo suas primeiras operações e suas respectivas conceitualizações, organizadas ao longo da história da física e que acompanham a matematização dessa ciência, assim como os problemas de compreensão e de interpretação aos quais elas deram lugar, em suma, suas atribulações. Pode-se distinguir várias etapas na história conjunta da causalidade e do determinismo: a constituição da causalidade física na mecânica e na física clássica; a formulação ulterior do determinismo 
no sentido laplaciano, e o pensamento de um ideal determinista estendido da mecânica à física e à ciência em geral; finalmente, as modificações e as críticas sofridas por essas noções, principalmente com a relatividade e a física quântica.

Já examinamos, em um trabalho complementar a este, a gênese da primeira dessas noções, a causalidade física. . A causalidade estabeleceu-se como categoria científica com a construção, na física e inicialmente na mecânica clássica, da causalidade diferencial em torno do conceito de tempo instantâneo e contínuo, principal variável da dinâmica. Como embasamento filosófico dessa noção encontram-se as idéias de relação de ordem e de sucessão temporal (cf. Debru, 2003), e esses dois aspectos estão presentes na explicitação do modo de ação da causa que provoca a mudança de movimento. Pode-se ver na segunda lei do movimento de Newton, nos Principia, o primeiro passo em direção à expressão da causalidade na lei do movimento; todavia essa interpretação é retrospectiva, mostrando-se diferente a concepção explícita de Newton que, com efeito, deixava de lado a consideração do modo físico de ação e, portanto, das causas físicas, na mudança de movimento, substituindo-as pelo recurso ao conceito de força, que ele não queria justificar, a não ser "matematicamente".

A consideração expressamente física da "causa da mudança de movimento" encontra-se na realidade no Traité de dynamique de d'Alembert e está estreitamente ligada a seu projeto de fundar a dinâmica unicamente sobre aquelas grandezas que descrevem o movimento e suas mudanças (mudanças que eram, a seus olhos, "o único problema da dinâmica"; cf. Alembert, $175^{8}$ [1743], Prefácio). O modo de ação causal poderia ser descrito, segundo d'Alembert, de maneira puramente física, sem recurso a causas "metafísicas", pela identificação do modo de ação, no momento mesmo em que a ação tem lugar, com o efeito dessa ação, que é a mudança de movimento. Essa concepção só podia efetivar-se com a expressão diferencial das variáveis da dinâmica, particularmente do tempo, e de seu "elemento", $d t$, durante o qual se produz a mudança, em uma representação geométrica da variação das grandezas espaciais em função do tempo.

Pode-se considerar que essa construção (geométrica) de d'Alembert da causalidade física (temporal e diferencial) e da significação física correlativa das equações do movimento corresponde à concepção que a física a seguir manterá duradouramente, a partir de Lagrange, ${ }^{2}$ que a adotou em sua Mécanique analytique, obra que acabaria constituindo a referência fundamental de todas as elaborações ulteriores da física mate-

1 Indicamos o estudo sobre a gênese da causalidade física, cf. Paty, 2004, do qual o presente trabalho é a continuação direta.

2 Todavia, diferentemente de d'Alembert, Lagrange fazia uso do conceito de força aplicada a um sistema físico (d’Alembert não retinha, de sua parte, mais que a força acelerativa ou motriz, definida pela própria mudança de movimento). Mas esta definição da força, traduzida na equação de Euler-Newton ( $F=m a$, onde $m$ é a massa e $a$ a aceleração, derivada segunda com relação ao tempo da variável de espaço), era a partir de então "metafísicamente neutra". 
mática e teórica. Entretanto, ao pôr em forma puramente algébrica (analítica) a teoria do movimento mecânico, as considerações sobre o modo de ação da causa não tinham mais a necessidade de serem explicitadas, pois se tornavam inerentes à significação física do elemento diferencial de tempo. Com Lagrange, a causalidade (física) está na própria forma das equações, sem necessidade de interpretação geométrica do elemento $d t$, que fixa as condições de utilização (cf. Paty, 2004). É nesse sentido que ele será tomado por toda a física teórica até a física quântica, como veremos adiante.

O segundo momento, pelo qual começamos esta exposição, concerne à idéia de determinismo, que adquire um sentido preciso no século xIX, sentido que em boa parte se imbrica com o "determinismo laplaciano". Laplace acrescenta à causalidade diferencial a consideração das condições iniciais, supostamente dadas: ele afirma a partir de então a aptidão, em princípio, de deduzir o passado ou o futuro em seu conjunto a partir daqueles elementos primeiros (as condições iniciais). Tanto a causalidade física como o determinismo laplaciano "funcionaram" inicialmente na formulação da física antes de receber sua denominação explícita. Ao aceitar essas noções metateóricas, os cientistas caíram freqüentemente na tentação de ver nelas categorias absolutas e intemporais, associando-as indissoluvelmente, esquecendo suas diferenças a ponto de confundi-las, seja para celebrá-las como insuperáveis, seja para sublinhar que seus fracassos ou sua caducidade implicam em "renúncias" do pensamento. Com efeito, os físicos do domínio quântico falam com freqüência indiferentemente de causalidade e de determinismo quando evocam as dificuldades das concepções clássicas com respeito à mecânica quântica, a propósito da significação probabilista ligada à "função de estado" (ou "função de onda"), como se o fato de que uma descrição teórica estivesse expressa em termos de probabilidades implicasse uma ruptura com o determinismo e a causalidade, que concernem a ambos sistemas físicos individualizáveis e identificáveis. Mas isto já pertence a nosso terceiro período de atribulações. Como quer que seja, os dois possuem, na física, significações distintas, mesmo se suas atribulações se acompanham solidariamente: o determinismo laplaciano pode ser visto como uma sistematização ou uma hipóstase da causalidade newtoniana.

Consideremos, a seguir, o terceiro período, que foi aquele da crítica e do questionamento da causalidade e do determinismo, sem que os físicos tivessem por isso abandonado a ambição a uma descrição científica do domínio concernido. Das duas noções, foi sobretudo a primeira, a causalidade, que conheceu uma importante transformação com o conhecimento das ações físicas retardadas e não mais instantâneas, ocasionadas pela teoria eletromagnética, e da qual a teoria da relatividade restrita deveria fornecer as razões teóricas. Com efeito, a causalidade relativística impôs restrições às possibilidades de relações espaço-temporais para os acontecimentos físicos, com diversas implicações, que se tornam mais exigentes com a relatividade geral, a 
qual suscita a idéia de completude teórica. A cosmologia estabelecida como ciência acrescenta a essas noções (causalidade, determinismo, completude) suas considerações próprias que tendem a fazê-las passar do status de categorias para teorias físicas àquele de propriedades gerais do universo material, ou seja, da própria natureza.

Ao mesmo tempo em que a física, clássica e relativística, tornava precisas essas noções, seus limites segundo nossas concepções apareceram em outros domínios. Uma primeira falha na significação e no alcance do determinismo no sentido usual apareceu com a consideração dos sistemas dinâmicos "não-lineares", deterministas, mas ao cabo de comportamento não-previsível, em razão da amplificação das pequenas diferenças nas condições iniciais. Veremos como a física pôde propor outras relações restritivas, além daquela do determinismo para uma trajetória, como aquela da estabilidade estrutural de uma família de trajetórias, que qualificam estritamente um sistema dinâmico dado. Mas foi com a física quântica que os ideais de causalidade e determinismo, tal como eles haviam podido ser compreendidos até então, conheceram sua mais grave "crise", a saber, seu fracasso, ainda que fosse segundo modalidades diferentes para a causalidade e para o determinismo. Percebe-se que a interrogação sobre os problemas propostos por esse questionamento deve dirigir-se diretamente para a relação entre $a$ causalidade, o determinismo e as grandezas fisicas invocadas. As grandezas em jogo na física quântica são de dois tipos: aquelas que correspondem à observação e se ligam com as grandezas clássicas (munidas das limitações de sua utilização quântica) e aquelas que figuram na teoria, cuja forma matemática permite estabelecer relações que correspondem aos conteúdos físicos efetivos, aqueles dos fenômenos quânticos. As primeiras, desde muito, são julgadas como mais físicas que as outras (em nome de um primado da observação sobre a abstração), entretanto, são as outras que são causais e relacionais. Isso pode ser indicativo de uma inversão a operar: compreender como sendo mais físico (e real) o que é causal e relacional, mesmo se fosse mais abstrato; o resto, isto é, as grandezas clássicas, imediatamente dadas, sendo auxiliares e circunstanciais...

\section{O IDEAL DETERMINISTA: A GAUSALIDADE FÍSicA MAIS AS GONDIÇÕES INIGIAIS}

A palavra "determinismo" é de uso relativamente recente. Encontra-se em certos textos de filósofos alemães do século xix, para exprimir uma idéia que já está presente, de fato, sob outras denominações, como predeterminado ou predeterminismo (praedeterminismus) e particularmente em Leibniz (determinação e razão determinante, praedelineatio) (Lalande, 1980 [1926], p. 222-3; Leibniz 1966 [1705], 1962 [1710]). A doutrina da necessidade de Leibniz sobre a imbricação das causas e dos efeitos coloca-se sob o signo da razão suficiente (que faz com que as coisas sejam tais quais são e não de outro 
modo), e é verdade que esta última subjaz à maior parte das concepções que reivindicam, com ou sem uma terminologia precisa, o determinismo (mesmo se Claude Bernard se opõe às concepções de Leibniz em nome da liberdade da ação humana, que aliás Leibniz não negava) (Bernard, 1879-1885, v. 1, p. 55-6o). ${ }^{3}$ A razão suficiente subjaz, em todo caso, à declaração de Pierre-Simon Laplace que seria mais tarde tomada para ilustrar o sentido mais preciso retido pelo determinismo, aquele de "determinismo laplaciano", do qual trataremos agora. Acerca desse sentido e desse termo, que se tornaram familiares aos cientistas e aos filósofos do século xx, os autores de dicionários filosóficos de referência, como os de André Lalande e de Paul Foulquié, ficam curiosamente mudos (cf. Lalande, 1980 [1926]; Foulquié, 1962). Talvez isso aconteça porque Laplace, no texto que se tornou célebre, não utiliza a palavra "determinismo", que só entrará na linguagem mais tarde. ${ }^{4}$ No entanto, é evidente que a declaração de Laplace serve de pano de fundo para as concepções dos dois principais cientistas franceses a difundir o determinismo no último terço do século xıx, Glaude Bernard, o fisiologista, e Henri Poincaré, matemático e físico, ambos cientistas-filósofos. Talvez também o uso da expressão "determinismo laplaciano" se expandiu, sobretudo, no curso do século xx por antítese, para designar aquilo a que a física quântica opunha fortes objeções, como veremos ao final.

Antes de relembrar a concepção exposta por Laplace do determinismo avant la lettre, é interessante assinalar que uma prefiguração bastante próxima se encontra expressa mais de sessenta anos antes, em um verbete da Encyclopédie escrito pela pena de d'Alembert. D'Alembert, que teve Laplace como discípulo, e que ele inspirará tanto na astronomia teórica (principalmente por suas Recherches sur la précession des équinoxes e também pelas Recherches sur divers points importants du système du monde) como por suas Doutes et questions sur les probabilités, que incitaram Laplace a aprofundar a teoria das probabilidades principalmente em vista de sua aplicação aos fenômenos físicos. 5 O próprio título do verbete que contém essa reflexão é significativo, pois ele evoca, se não as probabilidades que serão o embasamento da concepção de Laplace, pelo menos o acaso (primeiro objeto, cronologicamente, da teoria da probabilidade), pois que se trata do verbete "Fortuito", classificado pelo autor como ligado à metafísica (cf. Alembert, 1757).

3 Leibniz preservava essa liberdade, desde que tivéssemos o conhecimento dos fenômenos (por exemplo, em Leibniz, $1962[1710])$.

4. Muito utilizado por Claude Bernard em seu trabalho de 1865, esse termo só entrará no Dictionnaire de l’Académie française em 1878 .

5 Cf. Alembert, 1749; 1754-1756; 1821 [1767]; Paty, 1988b. Em Laplace, 1891 [1774], encontra-se a fórmula BayesLaplace. 
A questão do acaso e da causalidade tinha preocupado bastante os contemporâneos (principalmente Daniel Bernoulli e Euler), além do próprio d'Alembert, a propósito das conclusões que se podiam obter das coincidências ou conjunções, fortuitas em aparência, como a coplanaridade (no plano da eclíptica) das órbitas dos planetas do sistema solar e seu mesmo sentido de rotação em torno do Sol. A probabilidade de que se encontrasse nisso o efeito do acaso era bastante pequena, praticamente nula, $\mathrm{e}$ indicava, portanto, para d'Alembert, que deveria existir uma causa, que nós não conhecemos. Como se sabe, coube a Laplace tirar partido dessas coincidências supondo-as, também ele, causais e elaborando a partir delas sua "hipótese cosmogônica" ou teoria da nebulosa planetária, cujas partes se condensam sob a ação da gravitação. ${ }^{\mathbf{6}}$

Sobre a questão, posta em concurso pela Academia de Berlim, de saber "se as leis do movimento dos corpos são de natureza necessária ou contingente", d'Alembert se pronunciará sem equívoco a favor da primeira alternativa. Os fatos, mesmo os mais empíricos, adquiriam, a seus olhos, um caráter de necessidade oculta, cujo caráter racional seria estabelecido por um conhecimento ulterior. Ele escreveu no Discurso preliminar da Encyclopedie: "O Universo, para quem pudesse abarcá-lo de um só ponto de vista, não seria, se fosse permitido dizê-lo, senão um fato único e uma grande verdade" (Alembert, [1751] 2000, p. 98). Ele precisaria também, em "Elementos da ciência", um de seus grandes verbetes da Encyclopédie sobre o conhecimento, que esse ponto de vista (que será aquele da inteligência suprema, isto é, de Deus) não pode ser o do homem, que não pode ter essa visão imediata de uma totalidade indivisível e "teria a necessidade de percorrer [os objetos dessa totalidade] um após o outro, para adquirir um conhecimento detalhado" (Alembert, 1755). É útil indicar, desde aqui, uma diferença fundamental com relação à concepção de Laplace: a consciência, em d'Alembert, de uma distância irredutível entre o ponto de vista do conhecimento humano e a realidade imanente da natureza.

No verbete "Fortuito", portanto, d'Alembert começa por declarar que "estando tudo ligado na natureza, os acontecimentos dependem uns dos outros; a cadeia que os une é freqüentemente imperceptível, mas não deixa de ser menos real", e ele remete imediatamente ao verbete "Fatalidade", devido à pluma de seu colega enciclopedista, o abade Morellet, o qual, diga-se de passagem, não faz apelo senão a considerações naturais e de modo algum a potências irracionais. ${ }^{7}$ Ele prossegue com uma consideração

6 Cf. Laplace, 1799-1825; 1824; [1796]. Kant tinha proposto, antes de Laplace, uma hipótese no mesmo sentido; cf. Kant, 1984, [1755].

${ }_{7} \mathrm{O}$ que indica um sentido metafisicamente neutro de "fatalidade", pelo menos em certos pensadores do século das Luzes. Encontra-se também em Diderot e suscita a idéia de que esse sentido foi aquele considerado pelos autores de dicionários do século XIX, onde figura pela primeira vez a palavra "determinismo", dada como equivalente a "fatalis- 
que parece antecipar, ainda que em outros contextos, as considerações atuais sobre o "efeito borboleta" do "caos determinista". Veja-se, por exemplo:

Suponhamos um evento a mais ou a menos no mundo, ou mesmo uma única mudança nas circunstâncias de um evento, todos os outros ressentir-se-ão com essa alteração pequena, assim como um relógio se ressente inteiramente da menor alteração sofrida por uma de suas rodas (Alembert, 1757).

Note-se a imagem mecanicista, que nos lembra que esta reflexão é posta à mostra pelas pesquisas de d'Alembert sobre os encadeamentos de causalidade da mecânica e da astronomia. Esta última desemboca nas pesquisas em torno da atração universal newtoniana e do tratamento do problema da interação entre três corpos por cálculos em séries de perturbação, que serão levados a uma grande precisão por Laplace.

D’Alembert estabelece a seguir com precisão que essa ligação de eventos e de coisas é mútua e total, nada é negligenciável ou sem efeito "no sistema geral do mundo". É claro que essa ligação, que pode ser dita sistêmica, remete à unidade da natureza e da matéria, submetidas às mesmas leis gerais, essas "leis gerais da natureza" (em particular, aquelas do movimento), cujo estudo constituía então a "cosmologia", como o precisa d'Alembert no verbete da Enciclopédia com esse título. Trata-se de um sentido pós-copernicano, e numa época em que ainda não se podia imaginar que o Universo como totalidade seria um dia objeto de ciência. ${ }^{\mathbf{8}}$

D'Alembert continua ainda no verbete intitulado "Fortuito":

Quando existissem eventos sem efeito, se esses eventos não tivessem existido, o que lhes deu nascimento tampouco teria existido; a causa que os produziu não seria exatamente tal qual é, nem por conseqüência a causa dessa causa, e assim por diante.

Ele toma então o exemplo (orgânico desta feita) de uma árvore, suas folhas e suas raízes; a menor alteração desta última modificaria a constituição do conjunto:

Essa árvore é a imagem do mundo. [...] Suponhamos mil mundos que existem ao mesmo tempo, todos semelhante a este, e governados conseqüentemente pelas

mo", por exemplo, no dicionário de Bouillet de 1878 e no de Franck de 1844. Mas Foulquié, assim como Lalande, se contenta em censurá-los por essa identificação. Sobre o verbete "Fatalidade", cf. Morellet, 1756.

8 Os estudos sobre a formação ou a evolução de mundos celestes, tais como os de Kant e Laplace, receberiam a denominação de "cosmogonia" e isso será utilizado ainda por Poincaré, 1911. 
mesmas leis; tudo se passaria aí exatamente do mesmo modo. Os homens em virtude dessas leis fariam nos mesmos instantes as mesmas ações em cada um desses mundos (Alembert, 1757).

Neste ponto, d’Alembert faz intervir a ficção de uma inteligência superior, igual àquela que supõe ser do Criador (instância que será retomada por Laplace com seu Observador onisciente), e cuja função, em seu propósito, é dupla. De uma parte, ela permite conceber a unicidade absoluta dos encadeamentos de causalidade idênticos, fazendo ver nelas as séries paralelas; de outra parte, por oposição entre uma visão total e exterior e visões parciais, finitas, mas dotadas de consciência (do "sentimento interior"), ela permite manter a idéia (ou, em certo sentido, a ilusão?) da liberdade humana. Nos próprios termos de d'Alembert:

E uma inteligência diferente do Criador, que visse ao mesmo tempo todos esses mundos tão semelhantes, tomaria os habitantes por autômatos, ainda que eles não fossem e que cada um deles no seu íntimo estivesse seguro do contrário. $\mathrm{O}$ sentimento interior é, portanto, a única prova de que dispomos e de que podemos dispor de ser livres (Alembert, 1757).

Laplace, de quem falaremos agora, retomará a primeira função. A declaração de Laplace que definiu o que foi chamado a partir de então de "determinismo laplaciano" figura no início de seu Ensaio filosófico sobre as probabilidades, colocado como prefácio da segunda edição, de 1814, de sua Teoria analítica das probabilidades (cf. Laplace, 1812; 1814, p. vi-vii). Ela começa pelo enunciado do encadeamento causal segundo o tempo, isto é, da causalidade física no sentido da expressão diferencial de mudança do movimento, evidenciado pelos conhecimentos adquiridos na mecânica e na astronomia, e estendido ao conjunto de todos os corpos (e mesmo "seres") do Universo: "Devemos, portanto, considerar o estado presente do universo como o efeito de seu estado anterior e como a causa daquele que seguirá” (Laplace, 1814, p. vi-vii).

Intervém então a idéia de uma "inteligência suprema”, espécie de extrapolação infinita das capacidades intelectuais humanas (como é explicitamente dito um pouco mais adiante), que persegue o ponto de vista de um conhecimento acabado ideal.

Uma inteligência que, para um instante dado, conhecesse todas as forças das quais está animada a natureza e a situação respectiva dos seres que a compõem, se de outro modo ela fosse suficientemente vasta para submeter esses dados à análise, abraçaria na mesma fórmula os movimentos dos maiores corpos do universo e aqueles do mais leve átomo: nada seria incerto para ela, e o futuro, tal como o passado, estaria presente a seus olhos (Laplace, 1812; 1814, p. vii; grifo meu). 
Notemos o apelo a "um instante dado", isto é, ao conceito de tempo instantâneo e diferencial, e à "análise", que fornece as equações diferenciais causais (expressão da mútua ligação das grandezas em suas mudanças dinâmicas) que descrevem o estado instantâneo do universo, entre um instante dado $(t)$ e o instante que o segue imediatamente na continuidade $(t+d t)$. A mecânica e a astronomia ensinam que a integração do sistema diferencial fornece uma solução definida ou determinada, se dispomos (pela observação) dos valores das grandezas que fornecem a "situação respectiva" dos constituintes do sistema a um único instante dado qualquer (o instante presente no qual vivemos, por exemplo): é o que chamamos usualmente de "condições iniciais". Não se trata senão de extrapolar esse resultado, que está ao alcance dos "geômetras" no caso dos sistemas locais tais como no dos corpos do sistema solar, ao conjunto dos objetos físicos do universo.

Terminemos a citação de Laplace:

O espírito humano oferece, na perfeição que soube dar à astronomia, um fraco esboço dessa inteligência. Suas descobertas na mecânica e na geometria, juntamente com a da gravitação universal, colocaram-no ao alcance de compreender nas próprias expressões analíticas os estados passados e futuros do Sistema do mundo. (...) Todos seus esforços na procura da verdade tendem a aproximá-lo sem cessar à Inteligência que acabamos de conceber, mas da qual ele ficará sempre infinitamente afastado (Laplace, 1814, p. vi-vii).

É precisamente aqui que vão intervir as probabilidades, objeto do Ensaio filosófico que se inicia com essas considerações, e da Teoria analítica do qual ele é o prefácio. $\mathrm{O}$ conhecimento fornecido pela astronomia, exposto anteriormente por Laplace em seu Tratado de mecânica celeste e no seu Exposição do sistema do mundo, ${ }^{9}$ não é aqui mais que lembrado. Apesar de seu poder, ele está limitado em suas certezas por toda a extensão de ignorância que separa o que sabemos do conhecimento ideal evocado. O papel das probabilidades será o de fornecer um paliativo a esta ignorância, permitindo-nos avaliar-lhe o grau a partir do que sabemos, e é possível fazê-lo muito exatamente tirando proveito, também aí, dos recursos da análise, pela teoria analítica das probabilidades.

Aidéia do determinismo laplaciano funda-se, portanto, sobre a de causalidade físi$c a$, que ela se propõe a estender e a sistematizar em um conhecimento global e absoluto ao qual nada escaparia do que existe no universo material. Esse projeto toma corpo sob a dupla conjunção dos progressos da astronomia teórica e da teoria das probabilidades. 
Por um lado, a causalidade física da mecânica analítica aplicada à atração universal, juntamente com o domínio do cálculo de perturbação do problema dos três corpos, permitiu colocar na forma de equações o "Sistema do mundo" e, acrescentando a isso os dados das condições iniciais, conhecer o estado desse sistema, com um grau de precisão que pode ser, idealmente, tão grande quanto se queira. Conhecendo-se a lei dinâmica (a forma da atração da gravitação) e uma vez dominado o método da análise matemática (o tratamento do problema dos três corpos), bastava, com efeito, para chegar a uma maior exatidão, estender o campo dos objetos tomados em conta e de aprofundar o desenvolvimento da série de perturbação. Essa segurança era consolidada pelos cálculos astronômicos efetivos sobre a estabilidade do sistema solar, a qual parecia extrairse da solução das equações. ${ }^{10}$ Em outros termos, a causalidade se via estendida e generalizada de uma descrição local e parcial a uma descrição geral e global, ampliável ao "universo inteiro", concebido como o conjunto dos objetos que ele contém.

Por outro lado, a possibilidade de estimar exatamente as insuficiências dessa descrição por recurso ao cálculo de probabilidade dava ao conhecimento uma garantia de perfectibilidade indefinida. A probabilidade constitui, para o "determinismo laplaciano", um paliativo à ignorância. Sua função no conhecimento pode, nesse sentido, ser dita subjetiva, porque ela se liga ao ponto de vista do conhecimento parcial de um sujeito. Um conhecimento objetivo ideal deveria ser formulado sem recorrer às probabilidades.

Concluamos este ponto em algumas palavras. O "determinismo laplaciano" se propõe qualificativamente o conhecimento total e absoluto, entretanto bastante ideal: ele se coloca do ponto de vista do conhecimento (perfeito), cujos elementos conceituais são os da mecânica analítica, bem estabelecidos por ela: o espaço, o tempo, a massa e a forma dos corpos, a trajetória, a atração gravitacional... Supõe-se que a "inteligência superior" recorre também a esses elementos conceituais: são implicitamente concebidos como imanentes à própria natureza, e o determinismo (efetivo), ainda que se coloque do ponto de vista do conhecimento, identifica-se de fato com a necessidade, que será o "ponto de vista" inerente à natureza. Anecessidade é de certo modo antropomorfizada. Não se encontra, nesse determinismo, a idéia de que os conceitos bem estabelecidos da mecânica (ou da física clássica) poderiam ser insuficientes e substituídos um dia por outros, os quais modificariam a organização de nossos conhecimentos.

Essas características, próprias da concepção comum do "determinismo laplaciano", não foram postas em questão, nem mesmo analisadas e não apareceriam como

10 Resultado publicado no terceiro volume do Traité de mécanique céleste, que ocasionará a célebre resposta de Laplace a Napoleão Bonaparte (a quem o volume havia sido dedicado em 1803), segundo a qual ele não tinha necessidade da hipótese de Deus em suas equações. 
uma das tantas fraquezas, a não ser a partir de quando se evidenciaram as limitações da física clássica. Ao contrário, o determinismo seria considerado até então como uma cláusula da própria definição de ciência. É o que aparece nas declarações de Claude Bernard e de Henri Poincaré, pelo menos à primeira vista, pois suas concepções efetivas do determinismo são mais nuançadas que o determinismo laplaciano em sentido estrito.

As causas imediatas dos fenômenos, as quais não são senão as condições desses últimos, escreve por exemplo Claude Bernard em sua obra A ciência experimental, "são suscetíveis de um determinismo tão rigoroso nas ciências dos corpos vivos quanto nas ciências dos corpos brutos". A seguir, Bernard faz a seguinte precisão: "não há diferença científica alguma em todos os fenômenos da natureza, não é senão a complexidade ou a delicadeza das condições de sua manifestação que os tornam mais ou menos difíceis de distinguir ou precisar" (Bernard, 1890, p. 183). ${ }^{11} \mathrm{O}$ determinismo é aqui tomado como sinônimo de cientificidade (sendo assim uma exigência imposta à própria cientificidade), e o argumento está dirigido contra as concepções vitalistas. Citemos ainda o seguinte: "Eu me proponho a demonstrar que os fenômenos dos corpos vivos são, como o dos corpos brutos, submetidos a um determinismo absoluto e necessário" (Bernard, 189o, p. 40; grifo meu). É suficiente dizer que esse determinismo é antes de tudo a expressão da unidade da matéria e o reflexo de sua necessidade.

Quanto a Poincaré, é aparentemente sem reserva que ele se declarava "determinista absoluto", na medida em que identificava, como Bernard, a ciência e o determinismo. Em um dos textos de seus Dernières pensées (Últimos pensamentos), ${ }^{\mathbf{1 2}}$ ele exclamava:

A ciência é determinista, ela o é a priori; ela postula o determinismo, porque ela não poderia existir sem ele. Ela o é também a posteriori; se ela começou por postulá-lo como uma condição indispensável de sua existência, ela o demonstra a seguir precisamente por existir, e cada uma dessas conquistas é uma vitória do determinismo (Poincaré, 1913, cap. 8).

Poincaré é herdeiro de Laplace nas duas direções, da mecânica celeste e da teoria da probabilidade, e pode-se perfeitamente conceber que ele aceitava em grande medida o pensamento laplaciano de uma hipóstase da causalidade física. Sua posição é, entretanto, menos absoluta que a de Laplace, e ele deixa entender de maneira precisa

11 Cf. também as numerosas outras declarações de mesma natureza em Bernard, 1865; 1879-1885.

12 Como d'Alembert no texto citado precedentemente (e como Claude Bernard), Poincaré mantém a liberdade das ações humanas pela consciência: "É completamente impossível não agir como um homem livre quando se age, não se deve raciocinar como um determinista quando se faz ciência” (Poincaré, 1913, cap. 8). 
em seus textos, nos quais está em questão o determinismo dos fenômenos físicos, que as aproximações (sobre a descrição dos objetos e dos fenômenos a um instante dado) e as escolhas de convenções (de classificação de corpos quase semelhantes segundo relações de equivalência) são necessárias se se deseja expressar, para o universo, a influência de seu estado em um instante dado $t$ sobre um fenômeno no instante imediatamente seguinte, $t+d t$ (cf. Poincaré, 1970 [1905], p. 171).

A concepção do determinismo de Poincaré é, portanto, atenuada em relação à de Laplace, e a razão essencial é que ele não identifica o objeto do conhecimento e o objeto real, e defende que o primeiro é construído pelo pensamento. Além disso, diferentemente de Laplace, ele demonstrou que a estabilidade do sistema solar não é adquirida e não pode rigorosamente ser adquirida; ${ }^{\mathbf{3}}$ sabe também (por tê-lo igualmente descoberto) o efeito de pequenas variações das condições iniciais sobre os sistemas físicos "deterministas", descritos exatamente pelas equações diferenciais, cuja amplificação das pequenas variações nessas equações pode conduzir a valores arbitrários (Poincaré, 1913 [1881-1886]). Enfim, ele tem o conhecimento da teoria dos gases de Boltzmann e sabe que as configurações estáveis de um conjunto estatístico jamais são absolutas e que o "determinismo estatístico" apresenta tanto mais irregularidades quanto mais nos aproximamos do comportamento das moléculas individuais.

\section{As RESTRIÇÕES DA GAUSALIDAdE RELATIVÍSTICA OU O PONTO DE VISTA DA INVARIÂNGIA}

Com a mecânica newtoniana e a mecânica analítica, a lei da causalidade instantânea e diferencial não dava a direção do tempo, pois admitiam um espaço simultâneo e uma atração da gravitação instantânea à distância. A direção do tempo deveria ser acrescentada à teoria, do exterior, pela escolha do sentido do percurso dos planetas sobre suas órbitas, dado pela observação. A teoria eletromagnética, ao introduzir na física as ações retardadas, fixava o curso do tempo de uma maneira mais natural: os campos elétrico e magnético de propagação progressiva de Michael Faraday e a teoria do campo eletromagnético de James Clerk Maxwell impunham o sentido do tempo nas relações de causalidade. A causa precedia necessariamente o efeito, pois a velocidade de propagação dos campos era finita (sendo seu valor dado pela velocidade da luz no vazio).

A teoria da relatividade restrita exprimiu as restrições conceituais e teóricas desse estado de coisas colocando a mecânica e o eletromagnetismo em conformidade entre si e com essas restrições fundamentais. Einstein deu-lhes a forma mais universal e 
"econômica": essas restrições se resumiam a dois princípios que governam os fenômenos físicos e a forma de suas teorias: o princípio de relatividade (para os movimentos inerciais) e a constância da velocidade da luz no vazio. Isso acabava por dar uma forma mais ampla à relatividade dos movimentos inerciais, constatada para a mecânica: posta como princípio, ela será, de agora em diante, entendida como compreendendo também a invariância da velocidade da luz e as leis do eletromagnetismo. Essa transformação obrigou a modificar os conceitos-chave da física, tais como o espaço e o tempo (e, portanto, a velocidade), a massa e a energia etc. A nova cinemática relativística implicava o liame entre espaço e tempo, um espaço-tempo indissolúvel (o espaço-tempo de Minkowski), para o qual a velocidade da luz, limite absoluto das velocidades, adquire o estatuto universal de constante de estrutura.

A causalidade física era desse modo transformada de causalidade temporal (não relativística) em causalidade espaço-temporal (relativística), submetida à estrutura do espaço-tempo por uma condição sobre a separação espaço-temporal de dois pontoseventos suscetíveis de estarem ligados causalmente: seu intervalo quadridimensional deve ser negativo $\left(\Delta x^{2}-c^{2} \Delta t^{2} \leq 0\right)$. Com efeito, sua relação pode ser causal, se eles estão separados por uma distância $x^{2} \leq c^{2} t^{2}$, e é necessariamente não causal para $x^{2}>c^{2} t^{2}$. Dito de outro modo, as ações causais de um ponto (quadridimensional) do espaço-tempo a um outro são tais que o quadri-vetor que une esses pontos seja interior ao "cone de luz", definido pela equação $x^{2}=c^{2} t^{2}$. A região externa do cone de luz, que exclui ações causais, é não física. Esta propriedade relacional do tempo, que inclui sua direção, é integrada ao conceito de tempo físico; não é deixada para a observação ou para uma escolha convencional (cf. Paty, 1994).

A teoria da relatividade geral não fez mais que caracterizar de uma maneira mais específica a transformação operada sobre o tempo e a causalidade pela relatividade restrita, substituindo a estrutura quase-euclidiana ("plana”) do espaço-tempo de Minkowski por uma métrica espaço-temporal local, dada em todo ponto do espaçotempo pelo campo de gravitação nesse ponto; campo produzido por fontes de massaenergia. Com as teorias da relatividade restrita e geral, a questão do determinismo não se diferencia do que ela é na física clássica, a não ser pela modificação indicada da causalidade. Não faremos outras considerações acerca das conseqüências, para objetos particulares (como os "buracos negros") ou para o universo em seu conjunto, dos aspectos que acabamos de indicar, o que nos afastaria muito de nosso propósito.

Deve-se, entretanto, evocar um dos prolongamentos da teoria da relatividade geral que interessa de perto à questão da causalidade, e que é a noção de "completude" da teoria. Essa questão é diferente daquela do determinismo, porque ela se põe do ponto de vista da própria teoria e não de sua aplicação a objetos, e até ao conjunto dos objetos do universo. 
O conceito de completude foi introduzido na física por Einstein, em vários sentidos, dos quais não evocaremos aqui senão aquele que interessa à relatividade geral (cf. Einstein, [1946] 1949; Paty, 1988c; 1993a, cap. 10). A completude caracteriza o fato de uma teoria ser auto-consistente, emprestando o menos possível de elementos a instâncias que lhe sejam externas (e idealmente a nenhuma). Eis então uma perspectiva acerca da estrutura e do alcance de uma teoria física que fornece um critério de comparação entre teorias que tratam de um mesmo domínio de fenômenos. Entre várias teorias equivalentes para esse domínio, escolhe-se de preferência a mais "completa", como sendo a que se aproxima mais do objeto por ela visado, pois ela o exprime melhor que as outras em sua necessidade.

Einstein considerou essa noção (que é antes um meta-conceito) a propósito da relatividade geral, formulando a condição de covariância geral, que esvazia todo privilégio dos referenciais particulares: toda escolha destes últimos não pode ser mais que contingente e arbitrária em relação à realidade, que é independente do sujeito que a considera ou que a observa. Mas o problema pode ser posto para toda a teoria da causalidade física e até mesmo para a teoria newtoniana da gravitação. De fato, para Einstein, é com Newton que o programa da completude começa na física com o desenvolvimento moderno da idéia de causalidade: "a completude lógica do sistema de Newton reside em que as únicas causas de aceleração das massas de um sistema são as próprias massas" (Einstein, 1927, p. 275). Mas a causalidade é um conceito ainda muito rudimentar com respeito à natureza considerada em sua realidade profunda. Ela justapõe a lei causal a outros dados que lhe são independentes, como o espaço e o tempo absolutos considerados como continentes independentes, as massas e as propriedades dos corpos, as constantes (como a de gravitação) e as condições iniciais. Para Einstein, de uma maneira geral, a restrição de causalidade era ainda muito limitada. Ele indicava:

Eu acredito, de minha parte, que os eventos que se produzem na natureza são controlados por uma lei de ligação bastante mais estrita e estreita do que supomos hoje em dia, quando falamos de um evento que é a causa de um outro (Einstein \& Murphy, 1932, p. 104).

Segundo ele, em nossa afirmação de causalidade, separamos um evento do processo todo inteiro, limitando-nos a considerar o que se produz sobre uma fatia do tempo (cf. Paty, 1993a, p. 481-2).

A relatividade geral é mais completa que a dinâmica gravitacional de Newton, mas ela faz subsistir ao lado do tensor métrico dado pela teoria o tensor de energiamomento, cujo conteúdo é empírico, e ela não dá a justificação racional da constante de gravitação. Além disso, ela não inclui os outros campos clássicos como o campo eletromagnético. 
Uma teoria mais completa seria uma teoria mais unificadora e "teoricamente fechada". No horizonte do programa de completude teórica se descortina o projeto da unificação e da simplificação da física em seu conjunto. Para Einstein, uma teoria do campo completa, na direção de suas próprias pesquisas, seria uma teoria do campo e de sua fonte, que não deixaria nenhum parâmetro sem determinação e seria capaz em particular de engendrar suas próprias constantes fundamentais. Ele resumia esse projeto na seguinte reivindicação de princípio, muito assintótico: "não existem constantes arbitrárias". Isso significava, mais precisamente, que

a natureza é feita de tal modo que é possível pôr logicamente leis tão precisamente definidas que, no interior dessas leis, somente intervêm as constantes totalmente determinadas de modo racional (e não as constantes das quais se poderia mudar o valor numérico sem por isso destruir a teoria) (Einstein, 1949 [1946], p. $62-3)$.

Einstein fundava sua convicção, de que um tal programa não é desarrazoado, em sua "profunda fé na simplicidade, isto é, na inteligibilidade, da natureza". 14 Mas ele tinha consciência de que as condições de um tal programa estavam ainda longe de serem alcançadas. Era, em todo caso, o único ponto de vista que lhe parecia valer verdadeiramente a pena, pois correspondia àquele da necessidade do real.

Pode-se considerar que os esforços atuais dos físicos na física fundamental para elaborar teorias quânticas de campo de calibre (gauge), mais unificadas, mais englobantes e que reduzem o número de seus parâmetros livres, vão no sentido do programa de completude (cf. Paty, 1988c). Isso se dá de maneira à primeira vista curiosa, pois se trata de teorias quânticas, para as quais a causalidade e o determinismo clássicos não são mais válidos. De fato, parece que as teorias quânticas, quando consideradas do ponto de vista da própria teoria (o ponto de vista estrutural), e não daquele das previsões sobre as grandezas observáveis (ou se assim se quiser, do ponto de vista da predição, em vez daquele da previsão), são bastante mais restritivas que as teorias da física clássica. Nesse sentido, elas ilustram bem o ponto de vista da completude contra aquele do determinismo, ainda que não tenha sido nessa direção que Einstein tenha, de sua parte, pensado; muito pelo contrário. Mas esta é uma outra história.

14 Arthur Eddington escrevia, num sentido próximo: "a natureza seria medida segundo seu próprio padrão" (Eddington, 1935, p. 230). A posição de Eddington difere da de Einstein pelo fato de considerar que as leis gerais, além das particulares e das constantes fundamentais, podem ser deduzidas somente com base em considerações epistemológicas (no sentido de filosofia do conhecimento), ou seja, de que se pode ter delas um conhecimento a priori. Isso é evidentemente um apriorismo particular, mais radical do que aquele de Kant, que deixava espaço para a contingência (pois as leis particulares eram determinadas pela experiência). 


\section{Os SISTEMAS DINÂMIGOS NÃO LINEARES OU O DETERMINISMO SUPERADO PELA ESTRUTURAÇÃO GAUSAL}

Não diremos aqui mais que algumas palavras sobre os sistemas físicos ditos "deterministas" mas que não conduzem a previsões certas e são, antes, totalmente imprevisíveis. Para tais sistemas, que não são necessariamente muito complexos, pois o fenômeno já se apresenta com um pequeno número de graus de liberdade (a partir de três), são suficientes pequeníssimas variações na definição das condições iniciais para que os sistemas de equações causais e deterministas no sentido laplaciano (os sistemas de equações diferenciais não lineares) as amplificam enormemente, produzindo a nãoprevisibilidade. ${ }^{15}$ Esse comportamento, posto em evidência por Poincaré em seus trabalhos de astronomia teórica sobre o problema dos três corpos e revelado por suas pesquisas matemáticas sobre a resolução dos sistemas de equações diferenciais, pareceu corresponder às situações as mais freqüentes, não unicamente na mecânica, mas também na física de uma maneira geral (assim como em outras ciências, da química à estatística de populações).

Os estudos, hoje em dia bastante difundidos, de situações de caos determinista na natureza (na física, na meteorologia etc), e em particular a possibilidade de controlálas em laboratório, na continuidade dos trabalhos de David Ruelle e Floris Takens, permitiram caracterizar de maneira positiva esse tipo de fenômenos, ultrapassando a simples constatação de sua imprevisibilidade ao longo do tempo. ${ }^{\mathbf{1 6}}$

A aproximação que arriscamos acima entre a solidariedade causal de todos os eventos do universo, tal como d'Alembert o enunciou no século xviII (no verbete "Fortuito"), e o "efeito borboleta" das concepções de caos determinista que torna impossível ao longo do tempo toda previsão, por exemplo, em meteorologia, é, com efeito, muito significativa do fato de que a ausência de previsão possível, que deveria aparecer como um tipo de indeterminação, é devida, de fato, de certo modo, a um "determinismo absoluto", se a coerência do vocabulário permitisse aqui uma tal expressão, que imediatamente devemos corrigir. As batidas imperceptíveis de asas, que nos escapam, engendram efeitos que serão percebidos algum tempo mais tarde, muito longe daí, em razão da solidariedade das causalidades. Entretanto, já que são as condições iniciais

15 Convém referir aqui aos seguintes trabalhos: Poincaré, 1890; Hadamard, 1898; Duhem, 1981 [1906], $2^{\mathrm{a}}$ parte, cap. 3, § 3; Birkhoff, 1912. Também cabe referir aos trabalhos de outros autores, principalmente da "escola russa", que desenvolveram as pesquisas nessa direção. Refiro-me às seguintes obras: Dahan-Dalmelico; Chabert \& Chemla, 1992; Roque, 2001.

16 Cf. os trabalhos seguintes: Lorenz, 1993; Ruelle \& Takens, 1971; Ruelle, 1988; Bergé, Pomeau \& Vidal, 1988. E também os seguintes estudos: Franceschelli, 2001; Franceschelli; Paty \& Roque, no prelo. 
que não são, no fim das contas, exatamente conhecidas por nós, não estávamos em uma situação de determinismo em sentido próprio. O que a enorme generalidade de situações de amplificação arbitrária das pequeníssimas variações nas condições iniciais indica, em realidade, é o caráter geralmente inoperante do ideal determinista. Tais sistemas permanecem, no entanto, governados pelo encadeamento das causalidades, que é tomado freqüentemente, embora erroneamente, pelo determinismo.

Esses sistemas físicos, ditos “deterministas", não são, na realidade, mais que sistemas causais; e o que os estrutura é precisamente o sistema de suas equações diferenciais, transcrição dessa causalidade física. Em vez de continuar a falar, a seu propósito, de sistemas deterministas não-previsíveis, seria melhor sem dúvida dizer: sistemas causais no sentido clássico e sensíveis a pequenas variações das condições iniciais. Dito de outro modo, o "ideal determinista", mesmo para os sistemas físicos ou mecânicos clássicos, permanece muito afastado da realidade, e o "ponto de vista do conhecimento", antropocêntrico, que ele representa, assume muito limitadamente a necessidade da natureza. Sua capacidade de previsões é freqüentemente irrisória em relação às informações que esses sistemas receptam. O estudo de tais sistemas pode, na verdade, aportar conhecimentos bem mais ricos, se não nos deixarmos cercear pelas limitações de um pensamento determinista, e se pensarmos mais amplamente as predições de outra maneira permitidas pelas relações causais. Por exemplo, como Poincaré, que teve primeiro a idéia de se interessar pelo comportamento geral ("qualitativo") das soluções ou pelo comportamento de famílias de trajetórias em vez de uma só, ou ainda, como os conhecimentos mais recentes fazem ver, interessando-se pelos "atratores estranhos" que assinalam as propriedades estruturais de tais sistemas físicos no caso dos sistemas dissipativos.

\section{A FÍSICA QUÂNTICA OU A GRÍTICA DA GAUSALIDADE DIFERENGIAL E A LIMITAÇÃO DO DETERMINISMO}

A física quântica foi a ocasião para a crítica mais viva feita contra não somente o determinismo, mas também a causalidade. Com efeito, foi a causalidade clássica a primeira a mostrar suas insuficiências no domínio dos fenômenos quânticos, em razão das ações descontínuas introduzidas pelo quantum de ação de Planck. Desde 1906, Einstein tinha feito a constatação de que a teoria eletromagnética clássica era insuficiente para os fenômenos atômicos e radiativos, isto é, quânticos. Constatação confirmada por Paul Ehrenfest em 1911, e Poincaré, debruçando-se sobre a questão ao final do mesmo ano, foi conduzido ao diagnóstico decisivo de que, nesse domínio, a física não se deixava mais escrever pelas equações diferenciais. A irredutibilidade do quantum de ação, 
dificilmente aceita pelos físicos, e pelo próprio Max Planck, demandava um outro modo de descrição teórica que aquele das ações contínuas e da causalidade diferencial.

A partir de 1913, ao propor seu modelo teórico do átomo nuclear com níveis de energia discretizados, Niels Bohr enveredava pela via de uma abordagem “semiclássica”, que combinava a utilização da teoria clássica em certas condições e a regra da quantificação de energias descontínuas para os níveis do átomo nuclear, regra que permite dar conta da emissão e da absorção de radiação (segundo a lei de Planck e de Einstein, $\Delta E=h v)$. O "princípio de correspondência" efetuava a junção do novo modelo e da velha teoria, nos limites de sua aplicação possível, que definia a fronteira do novo domínio. A física do átomo e da radiação devia "renunciar ao modo de descrição causal", segundo as palavras posteriores de Bohr, isto é, renunciar a representar os níveis energéticos dos átomos em termos de trajetórias orbitais de elétrons em torno de núcleos, pelo menos desde que existisse passagem de uma órbita a uma outra. O modelo do átomo de Bohr era dual: ele admitia a descrição clássica para os estados estacionários, com conservação de energia, a descrição espaço-temporal das órbitas eletrônicas retendo então seu sentido; mas ele a rejeitava para as transições entre estados, que não eram mais descritíveis no espaço em termos da mudança (contínua) da trajetória. Essa dualidade lhe parecerá mais tarde, com a mecânica quântica, como um traço geral da possibilidade de se representar os fenômenos quânticos, da qual ele elaborará as considerações sob a forma de uma doutrina ou filosofia da "complementaridade". As duas descrições eram mutuamente incompatíveis, mas elas permitiam, quando aplicadas sucessivamente, dar conta dos fenômenos quânticos (cf. Bohr, 1961 [1929]; 1949 [1946]).

Quanto ao determinismo no sentido clássico, muito cedo apareceu igualmente que era impossível mantê-lo, não apenas por causa da ruptura da causalidade, mas pelo papel diferente que a probabilidade acabou tendo nesse domínio. Até então, a probabilidade tinha servido de simples paliativo para a ignorância em que nos encontramos, por exemplo, dos processos individuais com a mecânica estatística, mas o determinismo de princípio não foi afetado, e falava-se de "determinismo estatístico". Ora, parecia cada vez mais, para os fenômenos quânticos, que a probabilidade era um "meio indispensável de descrição", e que não se pode dispensar nem mesmo idealmente. Um diagnóstico muito lúcido havia sido estabelecido nesse sentido por Paul Langevin a partir de 1913 (cf. Langevin, 1923; Paty, 2002). Além disso, Ladislas Natanson, em 1911, e Paul e Tatiana Ehrenfest, pouco tempo depois, deram-se conta de que a estatística correspondente à lei de Planck da radiação do corpo negro era diferente daquela utilizada com as distribuições de probabilidades ordinárias (ela utilizava combinações e não arranjos de elementos, como se esses elementos não tivessem identidade própria). No final de 1916, ao propor seu ensaio de síntese teórica coerente dos processos quânticos, conhecida depois como a "primeira teoria dos quanta", que estabelecia, em parti- 
cular, as propriedades corpusculares da radiação da luz, justapostas às suas propriedades ondulatórias, Einstein foi levado a constatar a permanência do caráter probabilista das predições de sua teoria.

Longe de atenuar-se com os progressos teóricos, esse caráter probabilista dos fenômenos quânticos acabou sendo reforçado, a ponto de constituir o próprio embasamento da nova teoria "verdadeiramente quântica", a mecânica quântica que será proposta e se imporá a partir de 1926-1927. ${ }^{17}$ A natureza particular da probabilidade quântica, já indicada acima, foi precisada em 1924-1926 por Sathandra Nath Bose e Albert Einstein (para os "bósons", com a função simétrica de troca por permutação) e por Wolfgang Pauli, Enrico Fermi e Paul Dirac (para os "férmions”, com a função antisimétrica de troca por permutação). Ela foi remetida a uma "indistinguibilidade" fundamental ("ontológica", se desejarmos) das partículas ou sistemas quânticos idênticos. A interpretação probabilista da função de onda (ou função de estado), proposta por Max Born em 1926, era uma das pedras angulares da teoria, pois ela juntava as grandezas teóricas, de forma matemática, utilizadas para a descrição do sistema físico e concebidas como abstratas e indiretas, e as grandezas observadas (medidas) nos fenômenos. Essas grandezas, ligadas entre si pela equação de estado do sistema, eram a função de estado, representada por um vetor de um espaço de Hilbert, $y$, e as variáveis dinâmicas, representadas por operadores lineares que agem sobre a função de estado. O "princípio de superposição" estipula (em conformidade com as propriedades dos espaços de Hilbert) que toda superposição linear de soluções $\left(\psi_{i}\right)$ da equação é também uma solução possível, de sorte que a função de estado que é a solução mais geral da equação de estado é uma superposição linear do conjunto de autofunções, cada uma ponderada por um coeficiente, $\alpha_{i},\left(\psi=\sum_{i} \alpha_{i} \psi_{i}\right)$. A interpretação de Bohr estipulava que o módulo quadrado da autofunção (ou seja, $\left|\psi_{i}\right|^{2}$, sendo $\psi_{i}$ uma das soluções possíveis, para os "autovalores" $\lambda_{i}$ dos operadores $\Lambda$ que representam as variáveis dinâmicas) dá a probabilidade para que o sistema se encontre no estado $S_{i}$ considerado $\left(\alpha_{i}=\left|\psi_{i}\right|^{2}\right)$.

Os fenômenos quânticos tinham a partir de então uma teoria preditiva para descrevê-los, a mecânica quântica. Entretanto, a significação física das grandezas teóricas não parecia evidente e suscitava interpretações diversas, das quais não podemos fazer aqui a descrição. Essas interpretações não eram somente "físicas”, em termos de significação física das grandezas do "formalismo teórico". Elas se queriam também filosóficas, em termos de concepções gerais sobre o conhecimento. A interpretação mais corrente durante muitos decênios foi aquela que se chamou "interpretação de

17 Cf. sua apresentação ao mundo científico por seus vários fundadores ao Conselho de física Solvay de 1927 (cf. Institut Solvay, 1928). Considero aqui indistintamente as duas versões da nova teoria, a saber, a mecânica ondulatória e a mecânica quântica. 
Copenhague", formulada por Bohr em torno da doutrina da complementaridade. A idéia diretriz de Bohr era que nós não podemos conhecer os fenômenos quânticos senão por intermédio dos aparelhos de observação, os quais, sendo macroscópicos (para chegar à nossa percepção), obedecem à física clássica. Mas como os conceitos clássicos são insuficientes para descrever exatamente os fenômenos quânticos, em razão de suas limitações, deve-se fazer apelo às informações alternativas de descrições complementares (a de onda e partícula, a de posição e momento etc). Nessas condições, subsistia um problema para a causalidade: a equação de onda da teoria é diferencial e causal, mas ela se aplica a operadores, e não mais a simples funções de valores numéricos; a determinação física do sistema no momento de sua observação era a-causal, pois a medição escolhia de maneira descontínua uma só das autofunções das quais a função de estado teórica é a superposição linear: ela corresponde a uma transição súbita, aleatória, $\psi \rightarrow \psi_{i}$.

Quanto ao determinismo, o caráter probabilista lhe era oposto, seguindo um deslizamento de sentido em relação à definição usual tal como a consideramos acima. A mecânica quântica não podia satisfazer-se, qualquer que seja a interpretação que se lhe acrescentar, com um determinismo estatístico, pois as probabilidades são irredutíveis, ao contrário da mecânica estatística. A questão de fundo era aquela da possibilidade ou não de descrever eventos ou sistemas físicos individuais a partir de uma formulação probabilista. Seria necessário, então, distinguir a probabilidade, como forma teórica, e a estatística, como resultado experimental (uma distinção que praticamente ninguém fazia na época do vivo debate sobre a interpretação). Mas, a partir de então, não se tratava mais tanto de determinismo, quanto da natureza da realidade física, como isso se seguia do debate entre Bohr e Einstein. Para Bohr, era impossível conceber o objeto independentemente do sujeito; a causalidade e o determinismo perdiam, com efeito, seu sentido na ausência da separação objeto-sujeito, separação que Einstein, ao contrário, desejava manter. Bohr propunha "renunciar à representação intuitiva" dos fenômenos atômicos, "renunciar definitivamente ao ideal da causalidade" e "modificar totalmente nossa atitude com relação ao problema da realidade física" (cf. Bohr, 1949 [1946], p. 233). Einstein indicava, de sua parte, diante dos fenômenos complexos da mecânica quântica, que era necessário "alargar e refinar ainda nosso conceito de causalidade” (Einstein \& Murphy, 1932, p. 202).

Falava-se, portanto, de crise da causalidade, devido à "redução do pacote de ondas" ou da "projeção" da função de onda sobre uma só de suas componentes. Falavase também de "crise do determinismo" devido ao espectro de probabilidades atado a toda grandeza física, e de sua razão profunda, do ponto de vista teórico, que se liga ao caráter não-comutativo das grandezas dinâmicas e do qual as relações de indeterminação de Heisenberg eram as conseqüências. É assim que Max Born afirmava com 
força que o determinismo, isto é, a possibilidade de determinar antecipadamente os eventos futuros, é uma afirmação vazia de sentido. Ele explicava a razão disso nos seguintes termos: "para que ela tivesse um sentido, seria necessário que fossemos capazes de conhecer completamente o presente, o que está excluído" (Born, 1958, p. 200; cf. Einstein \& Born, 1969). Ele relacionava, com efeito, implicitamente, o conhecimento do presente em questão àquele das variáveis conjugadas (ou incompatíveis), que não podem ser conhecidas simultaneamente devido a suas relações de não-comutação e que fazem que o auto-estado de uma não pode ser um auto-estado da outra. Os valores atribuídos a essas variáveis como soluções da equação de estado estão submetidos às desigualdades de Heisenberg, intituladas às vezes de relações de incerteza ou de indeterminação (cf. Born, 1958, p. 200; cf. Einstein \& Born, 1972). Para remediar a indeterminação probabilista, os físicos (Louis de Broglie, David Bohm, Jean-Pierre Vigier e outros) propuseram acrescentar variáveis deterministas escondidas, mas não podemos abordar aqui esta questão (cf. Paty, 1993b).

A idéia expressa por Born, referindo-se ao conhecimento possível, é formulada em termos de medição por outros autores, como a filósofa Paulette Février. Uma teoria é dita determinista ou indeterminista, expõe ela, se, a partir de resultados de medições iniciais, é possível, ou não, "prever com certeza o resultado de qualquer outra medição ulterior" (Février, 1952, p. 86). Esta formulação tem o mérito de lembrar que o que está em questão no problema do determinismo tal como ele é posto são as variáveis conformes à medida. Pergunta-se, retrospectivamente, se as grandezas que possuem os conteúdos físicos mais significativos são as grandezas observáveis, de natureza necessariamente clássica, ou se não poderiam ser, ao contrário, as grandezas "matemáticas" da teoria que contêm todas as características adequadas à descrição dos fenômenos especificamente quânticos. O conhecimento não é dado somente na percepção, ele acontece sobretudo no entendimento. Aqui também os caracteres estruturais da teoria se mostram os mais ricos para a predição, mas também para a compreensão (cf. Paty, 2001). E se, mais profundamente que uma crise do determinismo, estivéssemos diante de uma crise de nossas representações? Deve-se necessariamente passar por grandezas clássicas para descrever sistemas quânticos? Ou então não será que uma inteligibilidade destes últimos é doravante possível diretamente a partir de grandezas abstratas da teoria e de suas propriedades relacionais, tão apropriadas para pensar os fenômenos quânticos e agir sobre eles?

Paul Langevin escrevia, nos anos 1930:

Não se trata, em realidade, de modo algum de uma crise do determinismo, mas antes de uma crise do mecanismo que tentamos utilizar para representar um domínio novo. Constatamos de fato a insuficiência, no microscópico, de noções e 
de idéias que eram bem sucedidas no macroscópico, que haviam sido criadas para seu uso e para seu contato por tantas gerações (Langevin, 1934, p. 35 ).

E ainda:

Antes que concluir pela ausência de determinismo na natureza, é mais simples dizer que a questão está mal posta e que a natureza não conhece um móvel corpuscular. Neste emprego da palavra corpúsculo, repleta de velhas heranças, existe por vezes uma fonte de confusões e de dificuldades (Langevin, 1939, p. 1),

Langevin refutava assim a idéia de uma incerteza nas leis da natureza e concluía, para os resultados da física quântica, que "não há nada no domínio do átomo, esse infinitamente pequeno, que corresponda à noção de objeto individualizável que a mecânica clássica introduziu" (Langevin, 1939, p. 1; cf. Paty, 1988a, p. 209). Langevin criticava o determinismo corpuscular, mecanicista, isto é, laplaciano, para melhor preservar um "determinismo" entendido no sentido amplo que encontramos, por exemplo, em Poincaré.

Mas o que aparece claramente com a física quântica é o liame que a noção de determinismo mantém com a representação ligada a um sistema de conceitos, no caso, o sistema de conceitos clássicos e mesmo mecânicos: a física quântica é, por essa razão, indeterminista. E, no entanto, sabemos hoje que nada na física é mais determinado (ou encerrado teoricamente) que as propriedades preditas pela teoria quântica, a partir da função de estado y, que é "completamente determinada" pela equação de estado, a qual é plenamente causal em sentido próprio, ou seja, expressa por uma equação diferencial. O único problema é o problema epistemológico da significação física dessa função de estado e das variáveis dinâmicas que lhe estão associadas, que possuem a forma de operadores e não a de variáveis numéricas.

\section{Conclusão. A exigência de negessidade}

Ainda que o percurso que acabamos de fazer na tentativa de esclarecer a gênese, as transformações de sentido e os problemas postos por noções gerais, como as de causalidade e determinismo a propósito da física, seja suficiente em si mesmo, convém agora concluir com algumas palavras.

Vimos a causalidade física ser proposta para acompanhar e justificar o ponto de vista dos conceitos apropriados aos fenômenos do movimento e da mudança. Toda a física se constituiu com base nessa noção, escolhendo por referência a ela os princípios e os conceitos próprios à sua matematização, e essa noção mesma adaptou-se, por sua 
vez, a essas novas exigências. Quanto à física quântica, se pensarmos bem, ela com efeito continuou nesse mesmo impulso, ao fazer passar a causalidade para o lado de suas grandezas estruturais (funções de estado e operadores), as quais possuem o conteúdo físico fundamental, aquele que faz a especificidade dos fenômenos e dos sistemas quânticos. Essa causalidade alargada se exprime nas relações entre as grandezas dinâmicas, que podem ser temporais (dir-se-á causalidade propriamente dita), ou independentes do tempo como variável explícita, por exemplo, nas relações de invariância ou de simetria (dir-se-á então antes relação funcional ou estrutural); mas não se vê diferença de natureza entre as duas. A causalidade, no sentido de evolução com o tempo das grandezas da física clássica, aparece como um caso particular da segunda, sempre útil nas situações tradicionais (trajetórias simples etc).

No que concerne ao determinismo, nós o vimos cristalizar-se e depois relativizarse, perdendo a precisão inicial que tinha feito sua fortuna, principalmente porque estava ligado a um ponto de vista particular do conhecimento, em dependência estreita a um sistema de conceitos fundado sobre representações clássicas e, portanto, pouco capacitado para libertar-se dessas últimas. É difícil manter a idéia de um determinismo absoluto que continuaria a ser atado a um ponto de vista conceitual particular. É certamente possível manter a exigência, mas ela se esvazia de sentido e não corresponde mais a uma aquisição efetiva de conhecimento. ${ }^{\mathbf{1 8}}$

Vimos, nas concepções que formularam essas noções ou que as criticaram, insinuar-se freqüentemente, mas raramente de maneira explícita, a noção de necessidade. Ao contrário do determinismo, que exprime uma exigência a partir de um ponto de vista, a necessidade não pode ser um ponto de vista, pois ela é a própria imanência da natureza e não pode, portanto, deixar de ser a mais difícil de formular. Ela não dependeria de um ponto de vista, mas de uma exigência: uma exigência da natureza refletida em nosso entendimento e, portanto, produzindo seus efeitos nas representações, com a possibilidade de transformar e de substituir essas representações por outras. A necessidade é, como o real, uma categoria hipotética e programática, de uma ordem dos fenômenos e da natureza, a qual produz restrições sobre nossas maneiras de apreender os fenômenos por meio de nossos conceitos e relações de conceitos (grandezas e equações). A atenção à necessidade da natureza é o que permitiu uma ciência do movimento e, por exemplo, que impôs a causalidade física (e a da natureza) e suas transformações. Pôde-se confundi-la com o determinismo, como Claude Bernard ou Henri Poincaré; mas cientistas a reivindicaram expressamente, de Albert Einstein a Jacques Monod. Ela pode ser também recusada em nome de uma impossibilidade de falar 
libertando-se de um ponto de vista particular ou pretendendo ter o conjunto de todos os pontos de vista possíveis.

Contudo, várias são as indicações provenientes da física, e principalmente de suas novas direções, quer se trate da relatividade ou da física quântica, e que parecem levar adiante essa exigência, para formular as teorias físicas, de colocar-se do ponto de vista de todos os pontos de vista possíveis, se se pensa na significação dos princípios e das propriedades de invariância e de simetria.

O ponto de vista da crítica das categorias, que pareciam bem estabelecidas e absolutas, tais como a causalidade ou o determinismo, ou ainda a objetividade, ou uma noção estreita de realidade, impôs-se mostrando o liame que essas noções meta-teóricas mantêm com os sistemas de conceitos e de representações, e seu caráter relativo com respeito a essas representações. Essa crítica foi realizada em nome da necessidade dos fenômenos, que parece impor-se como a instância à qual referir nossos conhecimentos, quaisquer que sejam, de outro modo, nossas escolhas preferenciais de interpretações. A partir de então, a crítica de concepções estreitas e caducas e a exigência da necessidade dos fenômenos ou do real deveriam ter como efeito recolocar essas noções "sobre suas próprias pernas", fazendo considerar os conceitos teóricos inteligíveis apropriados para situações novas.

Nessa perspectiva, as noções meta-teóricas ou categorias que parecem mais apropriadas para o programa da física atual são as de interdependência funcional (como extensão da causalidade) e de necessidade.

Traduzido do original em francês por Pablo Rubén Mariconda

Este trabalho e aquele já mencionado sobre a causalidade (Paty, 2004), ao qual este trabalho se segue, foram apresentados em conjunto numa exposição intitulada "Causalité et déterminisme en physique classique, relativiste e quantique. Tribulations et différences" na Journée "Causalité et relation fonctionelle" de L'Ecole Doctorale Savoirs Scientifiques, Université de Paris 7, Denis Diderot, França, em 13 de março de 2002; e no Séminaire "Realisme scientifique et causalité”, Centre de philosophie des sciences, Institut Supérieur de Philosophie, Université Catholique de Louvain, Bélgica, em 15 de março de 2002. Agradeço a Claude Debru, Michel Ghins e Laurence Viennot pelo interesse e pelas discussões sobre o assunto deste artigo.

Michel PATY Diretor de pesquisa emérito do CNRS, Equipe REHSEIS (UMR 7596), CNRS e Université Paris 7 - Denis Diderot, Paris, França. Professor Visitante do Departamento de Filosofia da Universidade de São Paulo. paty@paris7.jussieu.fr 


\section{ABSTRACT}

The idea of determinism, proposed to extend and generalize physical causality by adding to it the consideration of initial conditions, was built from then on as the ideal reference of all scientific knowledge and was considered as insuperable. However, this ideal was to be challenged in various directions: by the modifications consecutive to relativistic causality; "non linear" deterministic dynamical systems, the behavior of which can lead to totally unpredictable situations; problems with quantum physics ("reduction" of the state function and probabilistic predictions). The two last cases make evident the limits of the notions of causality and of determinism, by showing that actual knowledge can far exceed them, and suggest questions concerning the actual physical meaning of the magnitudes used in the theory. When we consider the magnitudes that are the more physically meaningful from the point of view of the characteristics of physical phenomena, causality appears differently and especially determinism is shown anthropologically centered and insufficient. We are led to another more meaningful category: necessity, which is independent of our conceptual and theoretical choices and has at the same time the capacity to regulate them.

KEYwords • Causality. Science. Completeness. Initial conditions. Determinism. Space.

Quantum physics. Physical magnitude. Invariance. Necessity. Relativity. Dynamical systems. Time.

\section{REFERÊNCIAS BIBLIOGRÁFIGAS}

Alembert, J. R. d'. Recherches sur la précession des équinoxes et sur la mutation de l'axe de la Terre dans le système newtonien. Paris, David, 1749.

. Recherches sur différents points importants du système du monde. Paris, $1754^{-1} 175^{6 .} 3 \mathrm{v}$.

. Eléments des sciences. In: Alembert, J. R. d’ \& Diderot, D. (Ed.). Encyclopédie ou Dictionnai-

re raisonné des sciences, des arts et des métiers. Paris, Briasson/David/Le Breton/Durant, 1755 v. 5, p. $491^{-7}$.

. Fortuit. In: Alembert, J. R. d’ \& Diderot, D. (Ed.). Encyclopédie ou Dictionnaire raisonné des

sciences, des arts et des métiers. Paris, Briasson/David/Le Breton/Durant, 1757 .v. 7, p. 95-8.

. Traité de dynamique. Paris, David, $175^{8}$ [174,3].

. Euvres philosophiques, historiques et littéraires. Paris, Belin, 1821. $5 \mathrm{v}$.

Doutes et questions sur les probabilités. In: . Euvres philosophiques, historiques et littéraires.

Paris, Belin, 1821 [1767].v. 1, p. 451-62.

Discours préliminaire de l'Encyclopédie. Introd. e notas de M. Malherbe. Paris, Vrin, 2000 [1751].

Alembert, J. R. d' \& Diderot, D. (Ed.). Encyclopédie ou Dictionnaire raisonné des sciences, des arts et des métiers. Paris, Briasson/David/Le Breton/Durant, 1751-1780. 177v. + 11 v. de pranchas. (Encyclopédie).

Bergé, P.; Pomeau, Y. \& Vidal, C. L'ordre dans le chaos. Vers une approche déterministe de la turbulence. Prefácio de D. Ruelle. Paris, Hermann, 1988.

Bernard, C. Introduction à l'étude de la médecine expérimentale. Paris, Baillière, 1865. . Leçons sur les phénomènes de la vie communs aux animaux et aux végétaux. Paris, Baillière, 1879$1885.2 \mathrm{v}$.

. La science expérimentale. Paris, Baillière, 1890.

Birkнoff, G. D. Quelques théorèmes sur le mouvement des systèmes dynamiques. Bulletin de la Société Mathématique de France, 4०, p. 3०5-27, 1912.

Вонr, N. Discussion with Einstein on epistemological problems in atomic physics. In: Schilpp, P. A. (Ed.).Albert Einstein, philosopher-scientist. La Salle, Open Court, 1949 [194,6]. p. 201-41. (The Library of Living Philosophers). 
Вонг, N. Atomic theory and the description of nature. Cambridge, Cambridge University Press, 1961 [1929]. Born, M. L'Europe et le monde d'aujord'hui. Neuchâtel, La Baconnière, 1958.

Collectif. Les nouvelles theories de la physique. Paris, [s.n.], 1939.

Dahan-Dalmelico, A.; Chabert, J.-L. \& Chemla, K. (Ed.). Chaos et déterminisme. Paris, Seuil, 1992.

Debru, C. Causalité, temporalité, fonction. Kant, Helmholtz, Mach. In: Viennot, L. \& Debru, C. (Ed.). Enquête sur le concept de causalité. Paris, PUF, 2003. p. 57-76. (Coleção Sciences, Histoire et Société).

Duнem, P. La théorie physique. Son objet, sa structure. Paris, Vrin, 1981 [1906].

Eddington, A. New pathways in science. Cambridge. Cambridge University Press, 1935.

Einstein, A. Newtons Mechanik und ihr Einfluss auf die Gestaltung der theoretishen Physik. Naturwissenschaften, 15 , p. 273-6, 1927 .

. Autobiographisches. Autobiographical notes. In: Schilpp, P. A. (Ed.). Albert Einstein, philosopher-scientist. La Salle, Open Court, 1949 [1946]. p. 1-95.

Einstein, A. \& Murphy, J. Epilogue: a socratic dialogue. In: Planck, M. (Ed.). Where is science going? Nova Iorque, Norton, 1932. p. 201-21.

Einstein, A. \& Bonn, M. Correspondance 1916-1955, commentée par Max Born. Trad. francesa de P. Leccia. Paris, Seuil, 1972 .

Espinoza, M. (Ed.). De la science à la philosophie. Hommage à Jean Largeault. Paris, L'Harmattan, 2001.

FÉvrier, P. L'état actuel du déterminisme et de l'indéterminisme dans les sciences. Paris, PUF, 1952.

Fleury, N.; Joffily, S.; Simões, J. A. M. \& Troper, A. (Ed.). Leite Lopes festchrift. A pioneer physicist in the third world. Singapura,World Scientific Publishers, 1988.

Foulquí, P. Dictionnaire de la langue philosophique. Com a colaboração de Raymond Saint-Jean. Paris, PUF, 1962.

Franceschelli, S. Construction de signification physique dans le métier de physicien: le cas du chaos déterministe. Paris, 2001. Tese (Doutorado em História da Ciência). Universidade Paris 7-Denis Diderot.

Franceschelli, S.; Paty, M. \& Roque, T. (Ed.). Epistémologie des systèmes dynamiques. Actes des Journées tenues à Paris en nov. 1999. No prelo.

HADAMARD, J. Les surfaces à courbures opposées et leurs lignes géodésiques. Journal de Mathématiques Pures et Appliquées, 5 a. série, 4 , p. 27 e ss., 1898.

Institut Solvay. Electrons et photons. Rapports et discussions du cinquième Conseil de physique tenu à Bruxelles du 24 au 29 octobre 1927 sous les auspices de l'Institut international de physique Solvay. Paris, GauthierVillars, 1928.

Kant, E. Histoire générale de la nature et théorie du ciel ou Essai sur la constitution et l'origine mécanique de l'Univers dans sa totalité traité d'après les principes de Newton. Trad., introd. e notas de P. Kersberg, A.-M. Roviello e J. Seidengart. Paris, Vrin, 1984, [1755].

KLein, E. \& Spiro, M. (Ed.). Le temps et sa flèche. Gif-sur-Yvette, Editions Frontières, 1994.

Lalande, A. Vocabulaire technique et critique de la philosophie. Paris, PUF, 1980 [1926].

Langevin, P. La physique du discontinu. Conférence faite à la Société française de Physique. 27 de novembro, 1913. In: La physique depuis vingt ans. Paris, Doin, 1923. p. 189-264. . La physique depuis vingt ans. Paris, Doin, 1923.

. La notion de corpuscules et d'atomes. Paris, Hermann, 1934.

. Les courants positiviste et réaliste dans la philosophie de la physique. Rapport à la réunion de

l'Union Internationale de Physique. 2 de junho de 1938 em Varsovie. In: Collectif. Les nouvelles theories de la physique. Paris, [s.n.], 1939. p. 231-54.

Laplace, P. S. Traité de mécanique céleste. Paris, [s.n.], 1799-1825.5 v.

Théorie analytique des probabilités. Paris, [s.n.], 1812.

Essai philosophique sur les probabilités. Parue comme introduction à la 2 ème éd. de la Théorie analytique... Paris, [s.n.], 1814 . 
Laplace, P. S. Exposition du système du monde. Paris, [s.n.], 1824, [1796].

Euvres complètes. Paris, Gauthier-Villars, 1878-1912. 14.v.

Mémoire sur les probabilités des causes par les événements. In: Euvres complètes. 1891

[1774].v. 8, p. 27-65.

Leibniz, G. W. Essais de Théodicée. Ed. de J. Jalabert. Paris, Aubier-Montaigne, 1962 [1710].

. Nouveaux essais sur l'entendement humain. Ed. de J. Brunschvicg. Paris, Garnier-Flammarion,

1966 [1705].

Lorenz, E. The essence of chaos. Londres, University College Press, 1993.

Merleau-Ponty, J. La science de l'Univers à l'âge du positivisme. Etude sur les origines de la cosmologie contemporaine. Paris, Vrin, 1983.

. Sur la science cosmologique. Conditions de possibilité et problèmes philosophiques. Paris, EDPSciences, 2003. (Coleção Penser avec les sciences).

Morellet, A. Fatalité. In: Alem bert, J. R. d' \& Diderot, D. (Ed.). Encyclopédie ou Dictionnaire raisonnédes sciences, des arts et des métiers. Paris, Briasson/David/Le Breton/Durant, 1756. v. 6, p. 422-9.

Paty, M. La matière dérobée. L'appropriation critique de l'objet de la physique contemporaine. Paris, Archives Contemporaines, 1988a.

D’Alembert et les probabilités. In: RASHED, R. (Ed.). Sciences à l'époque de la Révolution française. Recherches historiques. Paris, Blanchard, 1988b. p. 203-65.

. Sur la notion de complétude d'une théorie physique. In: Fleury, N.; Joffily, S.; Simões, J. A. M.

\& Troper, A. (Ed.). Leite Lopes festchrift. A pioneer physicist in the third world. Singapura, World Scientific

Publishers, 1988c. p. 14,3-64.

. Einstein philosophe. La physique comme pratique philosophique. Paris, PUF, 1993a.

Sur les variables cachées de la mécanique quantique: Albert Einstein, David Bohm et Louis de

Broglie. La Pensée, Paris, 292, p. 93-116, mar./abr. 1993b.

Sur l'histoire du problème du temps: le temps physique et les phénomènes. In: Kuein, E. \&

Spiro, M. (Ed.). Le temps et sa flèche. Gif-sur-Yvette, Editions Frontières, 1994. p. 21-58.

. Paul Langevin (1872-1946), la relativité et les quanta. Bulletin de la Société Française de Physique,

119, p. 15-20, maio 1999 .

. La notion de grandeur et la légitimité de la mathématisation en physique. In: Espinoza, M. (Ed.).

De la science à la philosophie. Hommage à Jean Largeault. Paris, L'Harmattan, 2001. p. 247-86.

. Poincaré, Langevin, Einstein. Épistémologiques, 2, 1-2, p. 33-73, jan./jun. 2002.

A gênese da causalidade física. Scientix Studia, 2, 1, p. 9-32, jan./mar. 2004.

Planck, M. (Ed.). Where is science going? Nova Iorque, Norton, 1932.

Poincaré, H. Sur les problèmes des trois corps et les équations de la dynamique. Acta Mathematica, 13, p. $1-270,1890$.

. Leçons sur les hypothèses cosmogoniques. Proferidas na Sorbonne, redigidas por Henri Vergne.

Paris, Hermann, 1911.

Mémoires sur les courbes définies par une équation différentielle. In: Euvres. Paris,

Gauthier-Villars, 1913 [1881-1886].v. 1, p. 3-44, 44-84, 90-158, 167-222.

. Dernières pensées. Paris, Flammarion, 1913.

. Euvres. Paris, Gauthier-Villars, 1913-1965. $11 \mathrm{v}$.

. La valeur de la science. Paris, Flammarion, 1970 [1905].

Popper, K. The open universe (The postscript to the Logic of scientific discovery, 2). Londres, Hutchinson, 1982.

RAshed, R. (Ed.). Sciences à l'époque de la Révolution française. Recherches historiques. Paris, Blanchard, 1988.

Roque, T. Ensaio sobre a gênese das idéias matemáticas: exemplos da teoria dos sistemas dinâmicos. Rio de Janeiro, 2001. Tese (Doutorado em História da Ciência). Universidade Federal do Rio de Janeiro. 
Ruelle, D. Hasard et chaos. Paris, Odile Jacob, 1988.

Ruelle, D. \& Takens, F. On the nature of turbulence. Communications in Mathematical Physics, 20, p. 16792, 1971.

Schilpp, P.A. (Ed.).Albert Einstein, philosopher-scientist. La Salle, Open Court, 1949. (The Library of Living Philosophers).

Viennot, L. \& Debru, C. (Ed.). Enquête sur le concept de causalité. Paris, PUF, 2003. (Coleção Sciences, Histoire et Société). 